\title{
Hubungan tingkat pengetahuan tentang kesehatan gigi dan mulut dengan tingkat kebersihan gigi dan mulut anak sekolah dasar
}

\author{
Etty Yuniarly a, ${ }^{*}$, Rosa Amalia ${ }^{b}$, Wiworo Haryani a \\ a Jurusan Keperawatan Gigi, Poltekkes Kemenkes Yogyakarta \\ b Fakultas Kedokteran Gigi, Universitas Gadjah Mada \\ ${ }^{1}$ yuniarly80@gmail.com* \\ *korespondensi penulis
}

\begin{tabular}{l}
\hline Informasi artikel \\
\hline Sejarah artikel: \\
Diterima \\
Revisi \\
Dipublikasikan \\
\hline
\end{tabular}

Kata kunci:

Tingkat pengetahuan tentang kesehatan gigi dan mulut Tingkat kebersihan gigi dan mulut

Anak sekolah dasar

\section{ABSTRAK}

Masalah kesehatan gigi dan mulut menjadi perhatian yang penting dalam pembangunan kesehatan yang salah satunya disebabkan oleh rentannya kelompok anak usia sekolah dari gangguan kesehatan gigi. Usia sekolah merupakan usia penting dalam pertumbuhan dan perkembangan fisik anak. Periode ini juga disebut sebagai periode kritis karena pada masa ini anak mulai mengembangkan kebiasaan yang biasanya cenderung menetap sampai dewasa. Salah satunya adalah kebiasaan menjaga kebersihan gigi dan mulut. Penelitian ini bertujuan mengetahui tingkat pengetahuan tentang kesehatan gigi dan mulut dan tingkat kebersihan gigi dan mulut anak sekolah dasar. Penelitian ini menggunakan observasional analitik dengan pendekatan cross sectional (potong lintang) yaitu merupakan rancangan dengan melakukan pengamatan pada saat bersamaan. Penelitian ini dilaksanakan di Sekolah Dasar Negeri Tuguran Kecamatan Gamping Kabupaten Sleman Daerah Istimewa Yogyakarta. Jumlah sampel sebesar 60 anak kelas III, IV, dan V yang diambil dengan metode purposive sampling. Pengumpulan data menggunakan kuesioner dan pemeriksaan kebersihan gigi dan mulut. Teknik analisis data menggunakan analisis uji korelasi Pearson Product Moment. Jumlah anak kelas III, IV, dan V SD Negeri Tuguran yang mempunyai tingkat pengetahuan tentang kesehatan gigi dan mulut kategori baik sebanyak $51,7 \%$ dan yang mempunyai tingkat kebersihan gigi dan mulut kategori sedang sebanyak $55 \%$. Hasil perhitungan analisis statistik dengan uji Pearson Product Moment dengan menggunakan tingkat kepercayaan 95\% $(\alpha=0,05)$ diperoleh hasil $\mathrm{Q}$-value $=0,000$, karena $\mathrm{Q}$-value $<\alpha$ maka Ho ditolak dan Ha diterima yang berarti ada hubungan tingkat pengetahuan tentang kesehatan gigi dan mulut dengan tingkat kebersihan gigi dan mulut. Ada hubungan tingkat pengetahuan tentang kesehatan gigi dan mulut dengan tingkat kebersihan gigi dan mulut pada anak sekolah dasar.

Key word:

The level of knowledge on oral health

Oral hygiene level

Elementary school children

\section{ABSTRACT}

Relationship of the level of knowledge on oral health with the level of oral hygiene elementary school children. Dental and oral health issues are an important concern in health development, one of which is caused by vulnerable groups of school-aged children from dental health disorders. School age is age important in growth and physical development of the child. This period is also known 
as a critical period because at this time the children start developing habits that usually tend to settle into adulthood. One of them is the habit of maintaining oral hygiene. This research aims to find out the level of knowledge on oral health and the level of oral hygiene elementary school children. This research use analytic observational approach cross sectional (cut the latitude) is a design by doing observations at the same time. This research was carried out in primary schools of the country Tuguran sub-district of Sleman Regency Limestone Daerah Istimewa Yogyakarta. Total sample of 60 children of class III, IV, and V were taken with purposive sampling method. Data collection using the questionnaire and examination of oral hygiene. Data analysis techniques using correlation analysis Pearson Product Moment test. The number of class III, IV, and V SD Negeri Tuguran have the level of knowledge on oral health good categories as many as $51.7 \%$ and level of oral hygiene medium category as much as 55\%. The results of the calculation of statistical analysis with Pearson Product Moment test by using a confidence level of $95 \%(\alpha=0.05)$ obtained results of $\mathrm{Q}$-value $=0.000$, because $\mathrm{Q}$-value $<\alpha$ then the Ho rejected and accepted Ha. There was a relationship of the level of knowledge on oral health with the level of oral hygiene in elementary school children.

This is an openaccess article under the CC-BY-SAlicense.

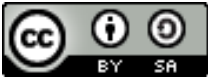

\section{Pendahuluan}

Masalah kesehatan gigi dan mulut menjadi perhatian yang penting dalam pembangunan kesehatan yang salah satunya disebabkan oleh rentannya kelompok anak usia sekolah dari gangguan kesehatan gigi ${ }^{1}$. Usia sekolah merupakan usia penting dalam pertumbuhan dan perkembangan fisik anak. Periode ini juga disebut sebagai periode kritis karena pada masa ini anak mulai mengembangkan kebiasaan yang biasanya cenderung menetap sampai dewasa ${ }^{2}$. Salah satunya adalah kebiasaan menjaga kebersihan gigi dan mulut. Perilaku anak Indonesia di dalam menjaga kesehatan rongga mulut masih rendah. Perawatan gigi dianggap tidak terlalu penting, padahal manfaatnya sangat vital dalam menunjang kesehatan dan penampilan ${ }^{3}$.

Menurut hasil Riset Kesehatan Dasar 2013, sebagian besar penduduk Indonesia menyikat gigi pada saat mandi pagi maupun mandi sore, $(76,6 \%)$ dan yang berperilaku benar menyikat gigi, yaitu sesudah makan pagi dan sebelum tidur malam sebesar 2,3\%. Sedangkan pada anak usia 10-14 tahun yang menyikat gigi setiap hari 95,7 \% dan yang menyikat gigi dengan benar yaitu sesudah makan pagi dan sebelum tidur hanya 1,7 \%4.

Salah satu penyebab timbulnya masalah kesehatan gigi dan mulut dalam masyarakat adalah faktor perilaku atau sikap mengabaikan kebersihan gigi dan mulut. Hal tersebut dilandasi dengan kurangnya pengetahuan tentang kesehatan gigi dan mulut serta perawatannya. Kesadaran seseorang akan pentingnya kesehatan gigi dapat dilihat dari pengetahuan yang dimiliki. Ketika seseorang memiliki tingkat pengetahuan yang tinggi maka perhatian untuk menjaga kesehatan giginya juga tinggi ${ }^{5}$.

Sebagai rumusan masalah apakah ada hubungan tingkat pengetahuan tentang kesehatan gigi dan mulut dengan tingkat kebersihan gigi dan mulut anak sekolah dasar Negeri Tuguran Kecamatan Gamping Kabupaten Sleman Daerah Istimewa Yogyakarta. Tujuan penelitian untuk mengetahui hubungan tingkat pengetahuan tentang kesehatan gigi 
dan mulut dengan tingkat kebersihan gigi dan mulut anak sekolah dasar Penelitian ini diharapkan dapat memberi manfaat, a. Bagi Institusi, sebagai bahan kajian atau masukan yang berguna bagi perkembangan ilmu pengetahuan khususnya ilmu kesehatan masyarakat, b. Bagi Jurusan/ Prodi, sebagai bahan kajian atau masukan yang berguna bagi perkembangan ilmu pengetahuan khususnya ilmu kesehatan gigi dan mulut anak, c. Bagi Dosen, meningkatkan tridharma perguruan tinggi dan sebagai bahan kajian atau masukan yang berguna bagi perkembangan ilmu pengetahuan khususnya ilmu kesehatan gigi dan mulut anak, d. Bagi Instruktur, menambah pengalaman dan wawasan dalam membantu penelitian dan sebagai bahan acuan praktek mata kuliah promosi kesehatan/ pendidikan kesehatan gigi, e. Bagi Mahasiswa, menambah pengalaman dan belajar tentang penelitian dan sebagai aplikasi mata kuliah metodologi penelitian, f. Bagi pihak Puskesmas sebagai bahan masukan agar dapat melakukan upaya peningkatan kesehatan terutama kesehatan gigi dan mulut pada anak sekolah, g. Bagi pihak sekolah sebagai bahan masukan agar dapat melakukan upaya peningkatan kesehatan terutama kesehatan gigi dan mulut pada anak didiknya.

\section{Bahan dan Metode Penelitian}

Jenis penelitian yang digunakan adalah penelitian observasional analitik dengan pendekatan cross sectional (potong lintang). Populasi dalam penelitian ini adalah semua anak SD Negeri Tuguran Kecamatan Gamping Kabupaten Sleman Daerah Istimewa Yogyakarta. Sampel penelitian adalah siswa kelas III, IV, dan V sebanyak 60 anak. Pemilihan sampel dengan metode purposive sampling. Variabel Pengaruh adalah tingkat pengetahuan tentang kesehatan gigi dan mulut. Variabel Terpengaruh adalah tingkat kebersihan gigi dan mulut. Proses pengumpulan data dilakukan dengan memberikan kuesioner tentang kesehatan gigi dan mulut dan melakukan pemeriksaan kebersihan gigi dan mulut. Teknik analisis data menggunakan analisis uji korelasi Pearson Product Moment.

\section{Hasil dan Pembahasan}

Tabel 1. Distribusi frekuensi karakteristik responden

\begin{tabular}{ccc}
\hline Karakteristik & Frekuensi & Presentase \\
\hline Usia & & \\
$8-10$ tahun & 42 & 70 \\
$11-13$ tahun & 18 & 30 \\
Jenis kelamin & & \\
Perempuan & 34 & 56,7 \\
Laki-laki & 26 & 43,3 \\
\hline Total & 60 & 100 \\
\hline
\end{tabular}

Tabel 1. menunjukkan bahwa berdasarkan usia diketahui jumlah responden paling banyak berusia 8 - 10 tahun yaitu 42 responden (70 \%) dan jenis kelamin responden lebih banyak adalah perempuan yaitu 34 responden (56,7\%).

Tabel 2. Tingkat pengetahuan responden

\begin{tabular}{ccc}
\hline Tingkat pengetahuan & Frekuensi & Presentase \\
\hline Baik & 31 & 51,7 \\
Cukup & 29 & 48,3 \\
Kurang & 0 & 0,0 \\
\hline Total & 60 & 100 \\
\hline
\end{tabular}

Etty Yuniarly et.al (Hubungan tingkat pengetahuan tentang kesehatan gigi dan mulut dengan tingkat kebersihan gigi dan mulut ) 
Tabel 2. menunjukkan bahwa responden memiliki tingkat pengetahuan tentang kesehatan gigi dan mulut terbanyak kriteria baik sebanyak 31 responden (51,7 \%).

Tabel 3. Tingkat kebersihan gigi dan mulut responden

\begin{tabular}{ccc}
\hline $\begin{array}{c}\text { Tingkat Kebersihan Gigi } \\
\text { dan Mulut }\end{array}$ & Frekuensi & Presentase \\
\hline Baik & 26 & 43,3 \\
Sedang & 33 & 55,0 \\
Buruk & 1 & 1,7 \\
\hline Total & 60 & 100 \\
\hline
\end{tabular}

Tabel 3. menunjukkan bahwa responden memiliki tingkat kebersihan gigi dan mulut terbanyak kriteria sedang sebanyak 33 responden (55\%).

Tabel 4. Tabulasi silang tingkat pengetahuan dengan usia responden

\begin{tabular}{|c|c|c|c|c|c|c|}
\hline \multirow{3}{*}{$\begin{array}{c}\text { Tingkat } \\
\text { pengetahuan }\end{array}$} & \multicolumn{4}{|c|}{ Usia } & \multirow{2}{*}{\multicolumn{2}{|c|}{ Total }} \\
\hline & \multicolumn{2}{|c|}{$8-$ I0 tahun } & \multicolumn{2}{|c|}{ II - I3 tahun } & & \\
\hline & $\mathrm{F}$ & $\%$ & $f$ & $\%$ & $f$ & $\%$ \\
\hline Baik & 21 & 35,0 & 10 & 16,7 & 31 & 51,7 \\
\hline Cukup & 21 & 35,0 & 8 & 13,3 & 29 & 48,3 \\
\hline Total & 42 & 70,0 & 18 & 30,0 & 60 & 100 \\
\hline
\end{tabular}

Berdasarkan tabel 4, dapat diketahui bahwa hasil tabulasi silang tingkat pengetahuan dan usia responden menunjukkan sebagian besar responden berusia 8-10 tahun memiliki tingkat pengetahuan kriteria baik dan cukup yaitu 21 responden (35\%).

Tabel 5. Tabulasi silang tingkat pengetahuan dengan jenis kelamin responden

\begin{tabular}{ccccccc}
\hline \multirow{2}{*}{$\begin{array}{c}\text { Tingkat } \\
\text { pengetahuan }\end{array}$} & \multicolumn{3}{c}{ Laki-laki } & \multicolumn{2}{c}{ Perempuan } & \multicolumn{3}{c}{ Total } \\
\cline { 2 - 6 } & $\mathrm{F}$ & $\%$ & $\mathrm{f}$ & $\%$ & $\mathrm{f}$ & $\%$ \\
\hline Baik & 10 & 16,7 & 21 & 35,0 & 31 & 51,7 \\
Cukup & 16 & 26,6 & 13 & 21,7 & 29 & 48,3 \\
\hline Total & 26 & 43,3 & 34 & 56,7 & 60 & 100 \\
\hline
\end{tabular}

Berdasarkan tabel 5, dapat diketahui bahwa hasil tabulasi silang tingkat pengetahuan dan jenis kelamin menunjukkan sebagian besar responden berjenis kelamin perempuan memiliki tingkat pengetahuan yang baik yaitu 21 responden (35\%).

Tabel 6. Tabulasi silang tingkat kebersihan gigi dan mulut dan usia responden

\begin{tabular}{ccccccc}
\hline \multirow{2}{*}{$\begin{array}{c}\text { Tingkat kebersihan } \\
\text { gigi dan mulut }\end{array}$} & \multicolumn{4}{c}{ Usia } & & \multirow{2}{*}{ Total } \\
\cline { 2 - 6 } & $\mathrm{F}-\mathrm{I}$ - tahun & $\%$ & $\mathrm{f}$ & $\%$ & $\mathrm{f}$ & $\%$ \\
\hline Baik & 17 & 28,3 & 9 & 15,0 & 26 & 43,3 \\
Sedang & 24 & 40,0 & 9 & 15,0 & 33 & 55,0 \\
Buruk & 1 & 1,7 & 0 & 0,0 & 1 & 1,7 \\
\hline Total & 42 & 70,0 & 18 & 30,0 & 60 & 100 \\
\hline
\end{tabular}

Berdasarkan tabel 6, dapat diketahui bahwa hasil tabulasi silang tingkat kebersihan gigi dan mulut dan usia responden menunjukkan sebagian besar responden berusia 8-10 tahun memiliki tingkat kebersihan gigi dan mulut kriteria sedang yaitu sebanyak 24 responden $(40 \%)$. 
Tabel 7. Tabulasi silang tingkat kebersihan gigi dan mulut dengan jenis kelamin responden

\begin{tabular}{ccccccc}
\hline \multirow{2}{*}{$\begin{array}{c}\text { Tingkat kebersihan } \\
\text { gigi dan mulut }\end{array}$} & \multicolumn{2}{c}{ Laki-laki } & \multicolumn{2}{c}{ Perempuan } & \multicolumn{3}{c}{ Total } \\
\cline { 2 - 5 } & $\mathrm{F}$ & $\%$ & $\mathrm{f}$ & $\%$ & $\mathrm{f}$ & $\%$ \\
\hline Baik & 10 & 16,6 & 16 & 26,7 & 26 & 43,3 \\
Sedang & 15 & 25,0 & 18 & 30,0 & 33 & 55,0 \\
Buruk & 1 & 1,7 & 0 & 0,0 & 1 & 1,7 \\
\hline Total & 26 & 43,3 & 34 & 56,7 & 60 & 100 \\
\hline
\end{tabular}

Berdasarkan tabel 7, dapat diketahui bahwa hasil tabulasi silang tingkat kebersihan gigi dan mulut dan jenis kelamin responden menunjukkan sebagian besar responden berjenis kelamin perempuan memiliki tingkat kebersihan gigi dan mulut kriteria sedang yaitu sebanyak 18 responden (30\%).

Tabel 8. Tabulasi silang tingkat kebersihan gigi dan mulut dengan jenis kelamin responden

\begin{tabular}{ccccccc}
\hline \multirow{2}{*}{$\begin{array}{c}\text { Tingkat kebersihan } \\
\text { gigi dan mulut }\end{array}$} & \multicolumn{2}{c}{ Laki-laki } & \multicolumn{2}{c}{ Perempuan } & \multicolumn{3}{c}{ Total } \\
\cline { 2 - 5 } & $\mathrm{F}$ & $\%$ & $\mathrm{f}$ & $\%$ & $\mathrm{f}$ & $\%$ \\
\hline Baik & 10 & 16,6 & 16 & 26,7 & 26 & 43,3 \\
Sedang & 15 & 25,0 & 18 & 30,0 & 33 & 55,0 \\
Buruk & 1 & 1,7 & 0 & 0,0 & 1 & 1,7 \\
\hline Total & 26 & 43,3 & 34 & 56,7 & 60 & 100 \\
\hline
\end{tabular}

Berdasarkan tabel 8, dapat diketahui bahwa hasil tabulasi silang tingkat kebersihan gigi dan mulut dan jenis kelamin responden menunjukkan sebagian besar responden berjenis kelamin perempuan memiliki tingkat kebersihan gigi dan mulut kriteria sedang yaitu sebanyak 18 responden (30\%).

Tabel 9. Tabulasi silang tingkat pengetahuan dengan tingkat kebersihan gigi dan mulut responden

\begin{tabular}{|c|c|c|c|c|c|c|c|c|}
\hline \multirow{3}{*}{$\begin{array}{c}\text { Tingkat } \\
\text { pengetahuan }\end{array}$} & \multicolumn{6}{|c|}{ Tingkat kebersihan gigi dan mulut } & \multirow{2}{*}{\multicolumn{2}{|c|}{ Total }} \\
\hline & \multicolumn{2}{|c|}{ Baik } & \multicolumn{2}{|c|}{ Sedang } & \multicolumn{2}{|c|}{ Buruk } & & \\
\hline & $\mathrm{f}$ & $\%$ & $f$ & $\%$ & $\mathrm{f}$ & $\%$ & $f$ & $\%$ \\
\hline Baik & 21 & 35,0 & 10 & 16,7 & 0 & 0,0 & 31 & 51,7 \\
\hline Cukup & 5 & 8,3 & 23 & 38,3 & 1 & 1,7 & 29 & 48,3 \\
\hline Total & 26 & 43,3 & 33 & 55,0 & 1 & 1,7 & 60 & 100 \\
\hline
\end{tabular}

Berdasarkan tabel 9, dapat diketahui bahwa hasil tabulasi silang tingkat pengetahuan tentang kesehatan gigi dan mulut dan tingkat kebersihan gigi dan mulut menunjukkan bahwa sebagian besar responden memiliki tingkat pengetahuan cukup dengan tingkat kebersihan gigi dan mulut kriteria sedang sebanyak 23 responden (38,3\%).

Untuk mencari adanya hubungan dan hipotesis antara variabel tingkat pengetahuan tentang kesehatan gigi dan mulut dan tingkat kebersihan gigi dan mulut maka diuji terlebih dahulu kenormalannya dengan uji Kolmogorov Smirnov. Apabila hasil diperoleh nilai p >0,05 maka data normal (Dahlan, 2008). Hasil uji normalitas data dalam penelitian ini didapatkan nilai $p$ value 0,299 >0,05 sehingga disimpulkan bahwa data memenuhi syarat normalitas. 
Tabel 10. Hasil Uji Korelasi Pearson Product Moment Tingkat Pengetahuan Kesehatan Gigi dan Mulut dengan Tingkat Kebersihan Gigi dan Mulut

\begin{tabular}{cccc}
\hline Variabel & Asymp Sig $(p)$ & Koef korelasi & $\boldsymbol{\alpha}$ \\
\hline Pengetahuan & 0,000 & $-0,489$ & 0,05 \\
$\begin{array}{c}\text { Kebersihan Gigi dan } \\
\text { Mulut }\end{array}$ & & & \\
\hline
\end{tabular}

Berdasarkan tabel 10. hasil perhitungan analisis statistik dengan uji Pearson Product Moment dengan menggunakan tingkat kepercayaan $95 \%(\alpha=0,05)$ diperoleh hasil $\rho$-value $=$ 0,000, karena $\rho$-value $<\alpha$ maka Ho ditolak dan Ha diterima yang berarti ada hubungan tingkat pengetahuan tentang kesehatan gigi dan mulut dengan tingkat kebersihan gigi dan mulut pada anak kelas III, IV, dan V SD N Tuguran Kecamatan Gamping Sleman. Nilai koefisiensi korelasi negatif (berlawanan arah) yaitu - 0,489 dan memiliki kekuatan hubungan yang sedang.

Berdasarkan tabel 1, dapat diketahui bahwa sebagian besar responden berusia 8-10 tahun memiliki tingkat pengetahuan kriteria baik dan cukup yang sama yaitu 21 responden (35\%), dan memiliki tingkat kebersihan gigi dan mulut kriteria sedang yaitu sebanyak 24 responden (40\%). Usia sekolah merupakan usia penting dalam pertumbuhan dan perkembangan fisik anak. Periode ini juga disebut sebagai periode kritis karena pada masa ini anak mulai mengembangkan kebiasaan yang biasanya cenderung menetap sampai dewasa ${ }^{2}$. Informasi tentang kesehatan gigi dan mulut yang diberikan kepada anak harus menggunakan bahasa yang mudah dimengerti oleh anak. Anak juga harus diberikan contoh mengenai cara-cara perawatan gigi sehingga anak akan menyukai hal-hal yang sering dilihatnya sehari-hari. Anak masih sangat memerlukan bimbingan dari orang tua sehingga anak mau melakukan sesuatu yang telah diketahuinya. Usia anak merupakan masa untuk meniru segala sesuatu yang dilihatnya, baik tingkah laku orang dewasa maupun sebaya. Anak belum dapat membedakan secara tepat tentang mana yang baik dan tidak terkait pengetahuan tentang tata cara perawatan gigi sebagai upaya menjaga kesehatan gigi dan mulut anak ${ }^{8}$.

Penelitian lain menyebutkan bahwa orang tua sangat berpengaruh dalam pembentukan perilaku anak. Sikap dan perilaku orang tua, terutama ibu, dalam pemeliharaan kesehatan gigi memberikan pengaruh yang cukup signifikan terhadap perilaku anak. Walaupun masih memiliki gigi sulung, orang tua harus memberikan perhatian serius pada anak. Pertumbuhan gigi permanen anak ditentukan oleh kondisi gigi sulung anak. Namun, masih banyak orang tua yang beranggapan bahwa gigi sulung hanya sementara dan akan digantikan oleh gigi permanen, sehingga mereka sering menganggap bahwa kerusakan pada gigi sulung bukan merupakan suatu masalah ${ }^{9}$.

Berdasarkan tabel 5 dan tabel 7, dapat diketahui bahwa sebagian besar responden berjenis kelamin perempuan memiliki tingkat pengetahuan yang lebih baik dibanding laki-laki yaitu sebanyak 21 responden (35\%), dan responden berjenis kelamin perempuan memiliki tingkat kebersihan gigi dan mulut kriteria baik 16 responden $(26,7 \%)$ dan kriteria sedang sebanyak 18 responden $(30 \%)$. Siswa berjenis kelamin perempuan lebih memperhatikan kebersihan gigi dan mulutnya dibandingkan dengan siswa berjenis kelamin laki-laki. Hal ini kemungkinan dapat disebabkan karena pada siswa perempuan memiliki kecenderungan untuk lebih menjaga penampilannya termasuk kebersihan gigi dan mulutnya sedangkan pada sebagian siswa laki-laki lebih tidak peduli dengan penampilannya.

Berdasarkan tabel 9. dapat diketahui bahwa sebagian besar responden memiliki tingkat pengetahuan cukup dengan tingkat kebersihan gigi dan mulut kriteria sedang sebanyak 23 responden ( $38,3 \%$ ). Tingkat pengetahuan yang cukup tanpa diikuti dengan kesadaran yang tinggi akan mempengaruhi kondisi kebersihan gigi dan mulut anak. Menurut ahli, suatu pengetahuan dipengaruhi oleh tingkat pendidikan, banyaknya informasi yang diperoleh, 
keadaan lingkungan, pengalaman, usia, dan status ekonomi seseorang. Hal ini karena pengetahuan dapat mempengaruhi sikap dan tindakan seseorang untuk mengaplikasikan informasi yang didapatkan untuk diwujudkan dalam kehidupan sehari-hari dan menjadi kebiasaan ${ }^{10}$. Terdapat dua aspek dalam pengetahuan, yaitu aspek positif dan aspek negatif. Kedua aspek ini berperan dalam menentukan sikap maupun perilaku terhadap obyek atau informasi yang diperoleh. Banyaknya aspek positif yang diperoleh semakin banyak pula sikap atau perilaku positif yang ditumbuhkan terhadap obyek tersebut ${ }^{11}$.

Berdasarkan tabel 10. hasil analisis Pearson Product Moment diketahui variabel tingkat pengetahuan dan tingkat kebersihan gigi dan mulut diperoleh nilai $p$-value sebesar 0,000 yang menunjukkan bahwa terdapat hubungan antara tingkat pengetahuan dengan tingkat kebersihan gigi dan mulut, dengan koefisiensi korelasi - 0,489 yang artinya semakin tinggi skor pengetahuan anak semakin rendah skor OHI-S nya atau semakin tinggi tingkat pengetahuan anak maka semakin baik tingkat kebersihan gigi dan mulutnya. Pentingnya peranan pengetahuan tentang kesehatan gigi dan mulut turut dalam membentuk perilaku dan sikap anak dalam menjaga kebersihan gigi dan mulutnya

Pengetahuan merupakan dasar terbentuknya suatu perilaku. Seseorang dikatakan kurang pengetahuan apabila dalam suatu kondisi tertentu tidak mampu mengenal, menjelaskan, dan menganalisis suatu keadaan ${ }^{10}$. Hal ini didukung oleh penelitian yang menyebutkan bahwa kesadaran seseorang akan pentingnya kesehatan gigi dapat dilihat dari pengetahuan yang dimiliki. Ketika seseorang memiliki tingkat pengetahuan yang tinggi maka perhatian untuk menjaga kesehatan giginya juga tinggi ${ }^{5}$.

Penelitian lain juga menyebutkan bahwa semakin tinggi pengetahuan mengenai kesehatan gigi maka semakin baik tingkat kebersihan gigi dan mulutnya. Sebaliknya semakin rendah pengetahuan mengenai kesehatan gigi, semakin jelek pula kebersihan gigi dan mulutnya. Keadaan ini dapat terjadi dikarenakan adanya beberapa faktor kesadaran dan perilaku menjaga kesehatan gigi dan mulut setiap individu ${ }^{11}$.

Analisis hubungan antara tingkat pengetahuan tentang kesehatan gigi dan mulut dengan tingkat kebersihan gigi dan mulut anak sekolah dasar dengan uji Pearson Product Moment menunjukkan adanya hubungan yang sedang dengan arah korelasi negatif $(-0,489)$. Oleh karena itu, pengetahuan tentang kesehatan gigi dan mulut pada anak sekolah penting karena dapat mempengaruhi kondisi kebersihan gigi dan mulut, dalam arti semakin tinggi tingkat pengetahuan anak tentang kesehatan gigi dan mulut maka akan semakin baik pula tingkat kebersihan gigi dan mulut anak tersebut.

\section{Kesimpulan}

Jumlah anak kelas III, IV, dan V SD Negeri Tuguran yang mempunyai tingkat pengetahuan tentang kesehatan gigi dan mulut kategori baik sebanyak 51,7 \%. Jumlah anak kelas III, IV, dan V SD Negeri Tuguran yang mempunyai tingkat kebersihan gigi dan mulut kategori sedang sebanyak $55 \%$. Terdapat hubungan antara tingkat pengetahuan dengan tingkat kebersihan gigi dan mulut anak kelas III, IV, dan V SD Negeri Tuguran

\section{Daftar Pustaka}

I. Warni L. 2009. Hubungan perilaku murid SD kelas V dan VI pada kesehatan gigi danmulut terhadap status karies gigi di wilayah Kecamatan Delitua Kabupaten Deli Serdang tahun 2009. Tesis. Universitas Sumatera Utara.

2. Hariyanti N, Palupi LS, Soejoko. 2008. Mengatasi Kegagalan Penyuluhan Kesehatan Gigi pada Anak dengan Pendekatan Psikologi. Dentika Dental Journal .13

3. Pratiwi D. 2009. Gigi Sehat dan Cantik. Kompas Media Nusantara, Jakarta

4. Kementerian Kesehatan RI. 2013. Laporan Riset Kesehatan Dasar. Badan Penelitian dan Pengembangan Kesehatan, Jakarta

Etty Yuniarly et.al (Hubungan tingkat pengetahuan tentang kesehatan gigi dan mulut dengan tingkat kebersihan gigi dan mulut ) 
5. Kawuryan U. 2008. Hubungan Pengetahuan tentang Kebersihan Gigi dan Mulut dengan Kejadian Karies pada Anak SDN Kleco II Kelas V dan VI di Laweyan Surakarta. Thesis. Fakultas Ilmu Kesehatan Universitas Muhammadiyah Surakarta

6. Notoatmodjo. 2010. Metodologi Penelitian Kesehatan. Jakarta. Rineka Cipta

7. Dahlan S. 2008. Statistik Untuk Kedokteran dan Kesehatan. Jakarta: Salemba Medika

8. Kozier B, Erb G, Berman A, Snyder SJ. 20I0. Buku Ajar Fundamental Keperawatan : Konsep, Proses \& Praktik. Jakarta: EGC

9. Rahayu TU. 2013. Pengaruh edukasi menggunakan Kartu Indikator Karies Anak (KIKA) terhadap perilaku ibu tentang pencegahan karies gigi sulung di Kelurahan Randusari Semarang. Jurnal Media Medika Muda KTI Semarang: Fakultas Kedokteran Universitas Diponegoro.

I0. Notoatmodjo, S. 2007. Kesehatan Masyarakat : Ilmu dan Seni. Jakarta. Rineka Cipta

II. Mintjelungan C., Tambunan E., Takahindangen S. 2013. Hubungan Pengetahuan Kesehatan Gigi dan Mulut dengan Status Kesehatan Gingiva pada Penyandang Tunanetra di Pani Tunanetra Manado. Skripsi. Fakultas Kedokteran Gigi Universitas Sam Ratulangi, Manado.

12. Safitri. 2015. Hubungan Tingkat Pengetahuan Frekuensi Menyikat Gigi terhadap Kebersihan Gigi dan Mulut pada Siswa Kelas IV SD N 28 Mataram. Gane CSwara Vol.O No. 2. 